\title{
Effect of nocturnal lighting on ethological and physiological traits of an ant
}

\begin{abstract}
Artificial nocturnal lighting affects the nature, an impact best studied on vertebrates that are directly depending on the presence or absence of light. Here, we examined on an ant species taken as a model the effects of artificial nocturnal lighting on eleven physiological and ethological traits. Ant workers maintained under nocturnal lighting showed a decrease or a change in their level of activity, food consumption, locomotion, orientation ability, audacity, tactile perception, social relationship, learning and memory. This was largely observed during the night but the effects persisted, at a lower extend, during the day
\end{abstract}

Keywords: aggressiveness, food consumption, learning, locomotion, memory, Myrmica sabuleti, orientation, sensitivity
Volume 4 Issue 5 - 2019

\author{
Marie-Claire Cammaerts,' Roger \\ Cammaerts $^{2}$ \\ 'Independent researcher, retired from the Biology of Organisms \\ Department, University of Brussels, Belgium \\ 2Independent researcher, retired from the Natural and \\ Agricultural Environmental Studies Department (DEMNA) of \\ the Walloon Region, Belgium
}

\author{
Correspondence: Marie-Claire Cammaerts, Independent \\ researcher, retired from the Biology of Organisms Department \\ University of Brussels, 27, square du Castel Fleuri, I I 70, \\ Bruxelles, Belgium, Tel 3226734969; \\ Email mccammaerts@gmail.com
}

Received: September 28, 2019 | Published: October 10, 2019
Abbreviations: ang.deg, angular degrees; ang.deg./cm, angular degrees per $\mathrm{cm} ; \mathrm{mm} / \mathrm{sec}$, millimeters per second; $\chi^{2}$, chi square; $v s$, versus; $\mathrm{n}^{\circ}$, number; $\mathrm{cm}$, centimeter; $\mathrm{mm}$, millimeter; min, minute; hrs, hours; \%, percentage

\section{Introduction}

Photopollution means artificial presence of light during the night and its consequences on the fauna, flora and ecosystems in general. Today, such light pollution tends to be worldwide and is particularly important in urban areas (Figure 1). Different causes of light pollution, the assessment of light intensities, several examples of extreme light pollution and some strategies deployed or proposed for reducing it are explained on the web (https://en.wikipedia.org > wiki > Light pollution). Here, we focus on the consequences that light pollution may have on the health and the biology of a living organism maintained first under normal daily lighting and nocturnal darkness conditions, then under daily lighting and moreover artificial nocturnal lighting conditions. Therefore, we performed physiological and ethological observations on an ant species used as a model and maintained under such lighting conditions.

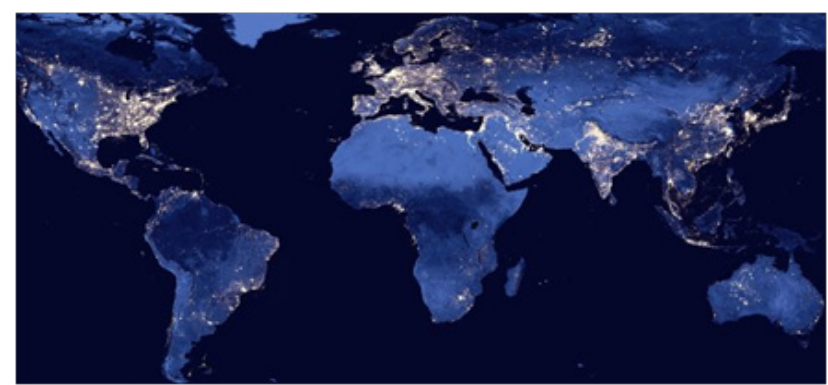

Figure I View of the earth at night, showing light pollution (courtesy NASA, Scientific Visualization Studio).
Of course, since more than one decade ago it has been shown that light pollution affects living organisms and their environment. The review of Longcore and Rich ${ }^{1}$ related the effects of astronomical (i.e. concerning the night sky view) and ecological (i.e. concerning the light regimes of ecosystems) light pollution on animal orientation, foraging, communication, reproduction, predation and other critical behaviors together with a consequent ecological impact. The negative health impact of light on night workers has also been documented. ${ }^{2}$ Concerning wild mammals, an interesting review relating their physiology and behavior to natural light-dark periods and to moonlight considers the observed and plausible consequences nocturnal light pollution may have on their life. ${ }^{3}$ Bats, which are nocturnal, are of course affected by the existence of light during night. ${ }^{4}$ Anthropogenic light at night has been shown to delay reproductive activation in the tammar wallaby. ${ }^{5}$ Experiments on rats used as models have clearly revealed the impact of constant (i.e. diurnal and nocturnal) light on their reproduction. ${ }^{6}$ Amphibians and reptiles have also been proved to be impacted by nocturnal light. ${ }^{7}$ A lot of works devoted to light pollution problems concern birds, which migration can be largely impacted. ${ }^{8}$ Nocturnal foraging of waders ${ }^{9}$ and nocturnal vigilance of peahens ${ }^{10}$ are also affected.

The ecological impacts of nocturnal lighting on vertebrates as well as on invertebrates have also been examined. ${ }^{11}$ It was demonstrated that street lighting affects the numerical composition of the invertebrate community, with a potential possibility that it alters the structure and function of the ecosystem. ${ }^{12}$ In an informative review of the impacts of artificial light at night on nocturnal insects, Owens and Lewis ${ }^{13}$ indicate temporal and spatial disorientation, fatal attraction, reduction of visual sensitivity by the saturation of the photoreceptors, failure of objects recognition as well as alteration of foraging activity and of species interactions. The best documented works on the impact of nocturnal artificial light on insects concern the negative effect of photopollution on the occurrence ${ }^{14}$ and courtship and mating success 
of fireflies, ${ }^{15}$ due to the reduction of their flashing activities. However, most works on insects do not or scarcely deal with physiological and ethological traits such as food intake, sensory perception, relationships between individuals, cognitive abilities, etc.

In the present work, we aimed to define the effects of nocturnal lighting on some physiological and ethological traits using an ant species as a model. We worked on the ant Myrmica sabuleti Meinert, 1861 of which, among others, the biology (recruitment, navigation, visual perception, etc.), ontogenesis of some abilities, cognitive abilities (solving some simple problems, etc.) numerosity ability (notion of zero, etc.) are rather well known. ${ }^{16-19}$ We can thus estimate the effect of any situation on several traits of this species. Effectively, we did so when examining the effects of products used by humans (up to now, the effects of 36 products have been examined), and each time, we found and explained the potential effects of the studied product. ${ }^{20-23}$ Here we examine the effect of nocturnal artificial lighting on eleven ethological and physiological traits of this ant: general activity, meat consumption, sugar water consumption, linear speed, angular speed, orientation, audacity, tactile perception, relation with nestmates, learning, and memory. We assessed these traits during the day and during the night, first on ants under normal lighting and thereafter, on the same ants under moreover nocturnal lighting. Using experimental devices and protocols already used in previous works, we shortly describe them, apologize for the inevitable plagiarism, and invite the readers to look for details in previous works. ${ }^{24-27}$

\section{Material and methods}

\section{Collection of ants}

The experiments were performed on two colonies of $M$. sabuleti, one collected at Marchin (Condroz, Belgium) in May 2018, the other in the Aise Valley (Ardenne, Belgium) in September 2018, each one in an abandoned quarry. We kept also in reserve two other colonies, collected at the same locations, in the case continuous lighting would drastically impact the ants' health. The colonies contained about 250 workers, a queen and brood. They were maintained in the laboratory in one to two glass tubes half-filled with water, a cottonplug separating the ants from the water. The glass tubes of each colony were set in a tray $(34 \mathrm{~cm} \times 23 \mathrm{~cm} \times 4 \mathrm{~cm})$, the borders of which having been slightly covered with talc to prevent ants escaping. The tray served as the ants' foraging area. Food was delivered in them as pieces of Tenebrio molitor larvae (Linnaeus, 1758) provided three times a week on a glass slide, and as a $30 \%$ sugar water provided in small tubes plugged with cotton and permanently deposited. Ambient temperature was $18^{\circ} \mathrm{C}-22^{\circ} \mathrm{C}$, relative humidity circa $80 \%$. At the time of this experimental work (end Augustus), the colonies lived under a natural 14:10h light-dark period. A window allowed such a natural lighting. In addition, an artificial lighting existed, provided by a Philips TLD 30W/33 white light tube. It gave an intensity of about 330lux, and was used while caring and experimenting the ants, as well as when additionally maintaining them continuously under nocturnal lighting. The ambient electromagnetic field had an intensity of $2-3 \mu \mathrm{W} /$ $\mathrm{m}^{2}$. The workers of a colony are named nestmates, as commonly do researchers on social hymenoptera.

\section{Experimental design and protocol}

All the assessments were first performed under normal lighting, i.e. the natural succession of light and dark periods, and thereafter under natural lighting during the day followed by artificial lighting during the night. For each of the two lighting conditions, assessments were made during the day and during the night. Each time, the values obtained during the day were compared to those obtained during the night. Then, the values obtained during the day as well as those obtained during the night under artificial continuous lighting were compared to the corresponding ones obtained under normal lighting (Tables 1-3); (Figure 2) (Figure 3).

Table I Effect of continuous lighting on general activity, meat and sugar water consumption. The table gives the daily means of four counts each time made over 30 minutes, and the means of these daily means. Continuous lighting impacted the three examined traits essentially during the night, but also during the day. Details and statistics are given in the text

\begin{tabular}{lllll}
\hline \multirow{2}{*}{ Traits Days } & \multicolumn{2}{l}{ Under normal conditions } & \multicolumn{2}{l}{ With nocturnal lighting } \\
\cline { 2 - 5 } & $\begin{array}{l}\text { during the } \\
\text { day }\end{array}$ & $\begin{array}{l}\text { during the } \\
\text { night }\end{array}$ & $\begin{array}{l}\text { during the } \\
\text { day }\end{array}$ & $\begin{array}{l}\text { during the } \\
\text { night }\end{array}$ \\
\hline Activity & 6.5 & 20.4 & 5.1 & 3.8 \\
2 & 7.7 & 16.1 & 5.2 & 4.2 \\
3 & 7.5 & 16.8 & 3.6 & 3.2 \\
4 & 7.8 & 16 & 1.3 & 2.3 \\
5 & 9.9 & 18.4 & 1.7 & 1.9 \\
6 & 8 & 18.3 & 2.3 & 1.9 \\
Mean & 7.2 & 17.7 & 3.2 & 2.9
\end{tabular}

Meat

\begin{tabular}{|c|c|c|c|c|}
\hline I & 0.7 & 3.4 & 1.8 & I \\
\hline 2 & 1.6 & 5 & 0.3 & 0.3 \\
\hline 3 & 2.2 & 4.4 & 0.3 & 0 \\
\hline 4 & 1.7 & 3.3 & 0 & 0.2 \\
\hline 5 & 1.2 & 2.8 & 0.3 & 0.2 \\
\hline 6 & 1 & 2.8 & 0.3 & 0 \\
\hline Mean & 1.4 & 3.6 & 0.5 & 0.3 \\
\hline \multicolumn{5}{|c|}{ Sugar water } \\
\hline I & 2 & 4.8 & 1.3 & 1.2 \\
\hline 2 & 2.7 & 4.4 & 1.9 & 2.4 \\
\hline 3 & 2.7 & 5.6 & 2.3 & 2.4 \\
\hline 4 & 2.8 & 6.4 & 2.3 & 1.7 \\
\hline 5 & 1.9 & 6.5 & 2.4 & 1.8 \\
\hline 6 & 1.8 & 6 & 2.3 & 1.9 \\
\hline Mean & 2.3 & 5.6 & 2.1 & 1.9 \\
\hline
\end{tabular}


Table 2 Impact of continuous lighting on five ethological or physiological traits. Each trait was impacted, essentially during the night. Details and statistics are given in the text. mm/sec: millimeters per second; ang.deg/cm: angular degrees per centimeter; ang.deg.: angular degrees; $n^{\circ}$ : number. The table gives the median (and the quartiles) or the mean [and the extremes] of the recorded values.

\begin{tabular}{|c|c|c|c|c|}
\hline \multirow{2}{*}{ Traits } & \multicolumn{2}{|c|}{ Normal conditions } & \multicolumn{2}{|c|}{ Continuous lighting } \\
\hline & $\begin{array}{l}\text { during the } \\
\text { day }\end{array}$ & $\begin{array}{l}\text { during the } \\
\text { night }\end{array}$ & $\begin{array}{l}\text { during the } \\
\text { day }\end{array}$ & $\begin{array}{l}\text { during the } \\
\text { 'night' }\end{array}$ \\
\hline $\begin{array}{l}\text { Linear speed } \\
(\mathrm{mm} / \mathrm{sec})\end{array}$ & $\begin{array}{l}10.3(9.6- \\
12.4)\end{array}$ & $\begin{array}{l}13.3(11.7- \\
15.2)\end{array}$ & $8.0(7.2-9.5)$ & $8.2(7.4-8.7)$ \\
\hline $\begin{array}{l}\text { Angular speed } \\
\text { (ang.deg./cm) }\end{array}$ & $|3|(|| 4-157)$ & $95(82-112)$ & $\begin{array}{l}165(148- \\
185)\end{array}$ & $\begin{array}{l}163(139- \\
188)\end{array}$ \\
\hline $\begin{array}{l}\text { Orientation } \\
\text { (ang.deg.) }\end{array}$ & $\begin{array}{l}44.9(35.2- \\
59.9)\end{array}$ & $\begin{array}{l}35.4(26.5- \\
49.9)\end{array}$ & $\begin{array}{l}62.2(40.1- \\
83.8)\end{array}$ & $\begin{array}{l}74.9(49.8- \\
83.9)\end{array}$ \\
\hline Audacity $\left(\mathrm{n}^{\circ}\right)$ & $1.25[0-2]$ & $5.00[3-6]$ & $0.80[0-2]$ & $1.05[0-2]$ \\
\hline $\begin{array}{l}\text { Tactile } \\
\text { perception }\end{array}$ & $\mathrm{I}=6.8(5.9-7.5)$ & $I=5 . I(4.6-5.6)$ & $\begin{array}{l}I=8.3(7.3- \\
9.3)\end{array}$ & $\begin{array}{l}I=7.2(6.7- \\
7.9)\end{array}$ \\
\hline $\begin{array}{l}\text { (I=linear speed, } \\
a=\text { angular speed) }\end{array}$ & $\begin{array}{l}a=198(178- \\
250)\end{array}$ & $\begin{array}{l}a=243(194- \\
274)\end{array}$ & $\begin{array}{l}a=180(164- \\
185)\end{array}$ & $\begin{array}{l}a=185(153- \\
200)\end{array}$ \\
\hline
\end{tabular}

Table 3 Impact of continuous lighting on two ethological traits. These traits were impacted during the night but also during the day, what was unexpected. Statistics and details can be found in the text. Aggressiveness levels: 0: doing nothing, I: contacting the opponent with the antennae, 2: opening the mandibles, 3: gripping the opponent, 4 stinging or trying to sting the opponent. Variable 'a'=numbers of levels $2+3+4 /$ numbers of levels I+2. hrs: hours. Unfulfilled experiment: memory could not been assessed since the ants did not learn.

\begin{tabular}{|c|c|c|c|c|}
\hline \multirow{2}{*}{ Traits } & \multicolumn{2}{|c|}{ Normal conditions } & \multicolumn{2}{|c|}{ Continuous lighting } \\
\hline & $\begin{array}{l}\text { during } \\
\text { the day }\end{array}$ & $\begin{array}{l}\text { during } \\
\text { the night }\end{array}$ & $\begin{array}{l}\text { during } \\
\text { the day }\end{array}$ & $\begin{array}{l}\text { during } \\
\text { the 'night' }\end{array}$ \\
\hline \multicolumn{5}{|l|}{ Relationships: } \\
\hline Aggressiveness levels 0 & 114 & 119 & 34 & 27 \\
\hline I & 68 & 53 & 46 & 46 \\
\hline 2 & 21 & 3 & 61 & 52 \\
\hline 3 & 0 & 0 & 1 & 3 \\
\hline 4 & 0 & 0 & 0 & 1 \\
\hline Variable 'a' & $a=0.12$ & $a=0.04$ & $a=0.78$ & $a=0.77$ \\
\hline \multicolumn{5}{|l|}{ Learning: } \\
\hline \multicolumn{5}{|l|}{ Conditioning scores } \\
\hline after $12 \mathrm{hrs}$ & - & $-70 \%$ & - & $50 \%$ \\
\hline $24 \mathrm{hrs}$ & $80 \%$ & - & $50 \%$ & - \\
\hline $36 \mathrm{hrs}$ & - & $85 \%$ & - & $50 \%$ \\
\hline $48 \mathrm{hrs}$ & $85 \%$ & - & $50 \%$ & - \\
\hline $60 \mathrm{hrs}$ & - & $-80 \%$ & - & $50 \%$ \\
\hline \multicolumn{5}{|l|}{ Memorization scores } \\
\hline $12 \mathrm{hrs}$ & $70 \%$ & - & & \\
\hline $24 \mathrm{hrs}$ & - & $70 \%$ & & \\
\hline 36hrs after cue removal & $80 \%$ & - & \multirow{3}{*}{\multicolumn{2}{|c|}{ unfulfilled experiment }} \\
\hline $48 \mathrm{hrs}$ & - & $70 \%$ & & \\
\hline $60 \mathrm{hrs}$ & $75 \%$ & - & & \\
\hline
\end{tabular}
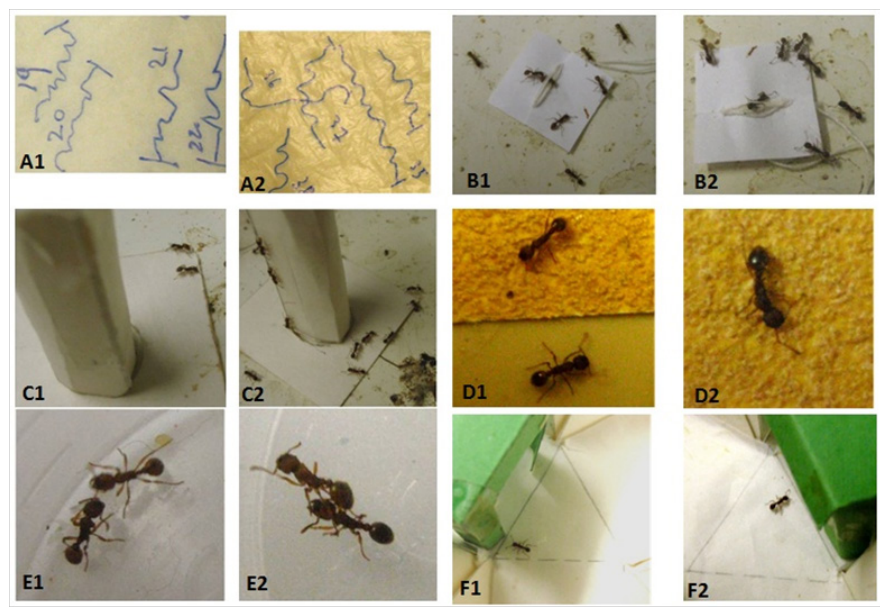

Figure 2 Some photos of the experiments made on ants living under normal (natural) lighting.

I: during the day, 2: during the night. A: ants' trajectories made during 5 seconds; those made during the night were somewhat longer and less sinuous than those made during the day. B: ants attracted by a tied nestmate; they better reacted during the night. C: ants' audacity; they were more inclined to come onto the risky apparatus during the night. D: ants' tactile perception; they more perceived the rough character of the substrate during the night, moving then with more difficulties. E: relationship; the ants were more inclined to stay side by side during the night. F: ants' conditioning; they equally correctly responded to the green cube during the day and the night.
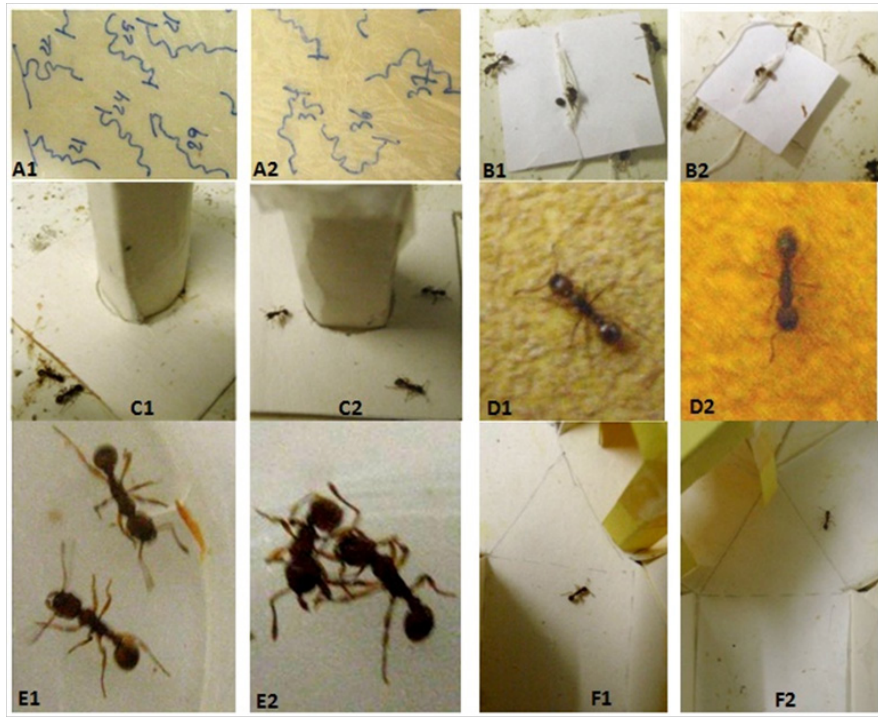

Figure 3 Some photos of the experiments made on ants living under additional nocturnal continuous lighting.

I: during the day, 2: during the night. A: ants' trajectories made during 5 seconds, they were short and sinuous. B: ants expected to come onto a tied nestmate, doing so poorly. C: ants little inclined to come onto an unknown risky apparatus. D: ants walking nearly normally on a rough substrate, weakly perceiving its uncomfortable character. E: nestmate encounters, with some signs of aggressiveness (i.e. E2: mandibles opening). F: an ant trained to a yellow cube hesitating in front of it (FI) and giving the wrong response (F2).

\section{General activity, meat and sugar water consumption}

During six days, the active ants present at any place of their environment, those present on the mealworm pieces, and those present at the entrance of the sugar water tubes were counted four times in the 
course of 30 minutes during the day and four times during the night For each of these counts, the daily mean value was established for each colony, then the mean of the six daily means was calculated (Table 1). For each kind of count, the six daily means obtained under normal lighting were compared to the six ones obtained under nocturnal artificial lighting using the non-parametric test of Wilcoxon. ${ }^{28}$

\section{Linear and angular speeds, orientation}

The assessments were made on ants freely moving on their foraging area. For the two kinds of speed, they were made without stimulating the ants and for the orientation, by presenting them a nestmate tied to a piece of paper (Figures 2B, 3B), which nestmate emitted then its attractive alarm pheromone. The trajectories were manually recorded during 5 seconds then copied on transparent sheets (Figures 2A, 3A) remaining affixed to a PC monitor screen due to their static electricity. They were analyzed using adequate software ${ }^{29}$ and the following definitions. The linear speed (V, measured in $\mathrm{mm} / \mathrm{s}$ ) is the length of a trajectory divided by the time spent to move along it. The angular speed or sinuosity (S, measured in angular degrees/ $\mathrm{cm}$ ) is the sum of the angles, measured at each successive point of the trajectory, made by each segment 'point $i$ to point $i-1$ ' and the following segment 'point $i$ to point $i+1$ ', divided by the length of the trajectory. The orientation $(\mathrm{O}$, measured in angular degrees) towards a given point is the sum of the angles, measured at each successive point of the recorded trajectory, made by each segment 'point $i$ of the trajectory - given point' and each segment 'point $\mathrm{i}-$ point $\mathrm{i}+1$ ', and divided by the number of measured angles. When $\mathrm{O}$ is lower than $90^{\circ}$, the animal has a tendency to orient itself towards the point; when it is larger than $90^{\circ}$, the animal has a tendency to avoid the point. Each distribution was characterized by its median and quartiles (Table 2) and the distributions obtained, during the day as well as during the night, for ants living under normal lighting and for those living under artificial continuous lighting were statistically compared using the non-parametric $\chi^{2}$ test. $^{28}$

\section{Audacity}

Acylindrical tower (height $=4 \mathrm{~cm}$; diameter $=1.5 \mathrm{~cm}$ ) tied to a squared platform $\left(9 \mathrm{~cm}^{2}\right)$, both in white Steinbach ${ }^{\circledR}$ paper, was deposited in the ants' tray, and the ants present on this unknown risky apparatus were counted 10 times over 10min (Figures 2C, 3C). The counts obtained for the two colonies were added, and the mean count as well as the obtained extreme values were established (Table 2, line 4). The 10 chronologically obtained counts were arranged and summed by 2 , and the 5 resulting sums were used for making the required comparisons (day vs night; normal lighting vs nocturnal lighting), and this was performed using the non-parametric test of Wilcoxon. ${ }^{28}$

\section{Tactile perception}

For evaluating the ants' tactile perception, we assessed their linear and angular speeds as explained here above (Linear and angular speeds, orientation) but this time on a rough substrate. On such an uncomfortable substrate, the ants with an intact tactile perception walked cautiously, with difficulty, slowly and sinuously while those having their tactile perception reduced walked more frankly, more rapidly and less sinuously. For each colony, the following apparatus was used. A folded piece $[3 \mathrm{~cm} \times(2+7+2) \mathrm{cm}]$ of emery paper $\mathrm{n}^{\circ} 280$ paper was tied to the bottom and the borders of a tray $(15 \mathrm{~cm} \times 7 \mathrm{~cm} \times 4.5 \mathrm{~cm})$, the latter becoming so divided in a first $3 \mathrm{~cm}$ long zone, a second $3 \mathrm{~cm}$ long zone having the emery (rough) paper as substrate, and a last $9 \mathrm{~cm}$ long zone. ${ }^{24-27}$ To perform an experiment,
12 ants of each colony were transferred into the first zone of their apparatus and 24 trajectories of ants walking on the emery paper were recorded. These 24 ants' linear and angular speeds were assessed; the median and quartiles of the obtained distributions of values were established, and these distributions were used to make the required comparison using the non-parametric $\chi^{2}$ test. $^{28}$

\section{Social relationship}

For approaching this trait, we evaluated the ants' potential aggressiveness against their nestmates as we did in previous works. ${ }^{24-27} \mathrm{We}$ did so in the course of five dyadic nestmate encounters performed for each two colonies in a cylindrical cup (diameter $=2.5 \mathrm{~cm}$, height $=1.8 \mathrm{~cm}$ ) the border of which having been slightly covered with talc. These encounters lasted five minutes during which we counted the number of times the observed ant did nothing (level 0 of aggressiveness), contacted the opponent with its antennae (level 1), opened its mandibles (level 2), gripped the other ant (level 3), and tried to sting or stung the opponent (level 4). The numbers obtained during the 10 encounters were added and the ants' aggressiveness was also evaluated by the variable "a", i.e. $n^{\circ}$ of aggressiveness levels $2+3+4 / \mathrm{n}^{\circ}$ of levels $0+1$. The added numbers of each five levels of aggressiveness, obtained at day and at night under the two kinds of lighting were compared and their difference statistically estimated using the non-parametric $\chi^{2}$ test. $^{28}$

\section{Learning and memory}

The ants were conditioned to respond to a visual cue by setting, at a given time, on the entrance of their sugar water tube, a green hollow cube for ants living under normal light, and a yellow hollow cube for ants living under artificial continuous lighting. The ants were then tested, at given times, in a Y-apparatus provided with a new, never used, green or yellow hollow cube in one of its branch. The Y-apparatus was made of strong white paper and was located in a separate tray $(30 \mathrm{~cm} \times 15 \mathrm{~cm} \times 4 \mathrm{~cm})$. The green or yellow cube was randomly located in the right or the left branch of it. For testing one ant, the latter was deposited at the entrance of the $\mathrm{Y}$ apparatus and it was noted into which branch it moved, moving into the branch containing the cube being considered as giving the correct response (Figures 2F, 3F). After the test, the ants were deposited in a glass cup until ten ants of their colony were tested. In total twenty ants were tested, what allowed establishing the proportion of correct responses ( $=$ the ants' conditioning score). Five testing sessions were conducted for each lighting condition and their results $(\mathrm{N}=5)$ were compared using the non-parametric Wilcoxon test. ${ }^{28}$ Then, after removal of the visual cue, five more testing sessions were performed under normal lighting. However, this could not be done for artificial continuous lighting since under that lighting condition no learning occurred.

\section{Results}

\section{Synopsis}

We successively

a. Relate the results obtained under normal (natural) lighting, comparing those obtained during the day to those obtained during the night.

b. Relate the results obtained with additional nocturnal continuous artificial lighting, comparing those obtained during the day to those obtained during the night. 
c. For each examined trait, compare the results obtained with the additional nocturnal artificial lighting to the corresponding ones obtained under normal lighting, during the day as well as during the night.

\section{Under normal (natural) lighting, results obtained during the day and the night}

General activity, meat and sugar water consumption: Numerical results are given in Table 1, left part. Under normal lighting, the ants appeared to be largely more active during the night than during the day. Meanly, over six assessments, 17.7 active ants were counted during the night and 7.9 ones during the day, a significant difference $(\mathrm{N}=6, \mathrm{~T}=21, \mathrm{P}=0.016)$. In the same way, the ants consumed more meat during the night than during the day. Meanly, 3.6 ants were seen on the pieces of mealworm during the night while 1.4 ants were seen there during the day. This difference was also statistically significant $(\mathrm{N}=6$, $\mathrm{T}=21, \mathrm{P}=0.016$ ). Also, the ants consumed significantly more sugar water during the night than during the day. Over the six experimental days, meanly 5.6 ants were counted at the entrance of the sugar water tube during the night while 2.3 ants were counted at that place during the day $(\mathrm{N}=6, \mathrm{~T}=20, \mathrm{P}=0.031)$. Thus, under normal lighting, the ants were more active and eat more during the night than during the day.

Linear and angular speeds: Numerical results are given in Table 2, lines 1 and 2; two photos are shown in Figure 2. Under normal lighting, the ants appeared to walk more rapidly and less sinuously during the night than during the day. These two differences were significant, the results being, for the linear speed: $13.3 v s 10.3 \mathrm{~mm} / \mathrm{sec}\left(\chi^{2}=23.12\right.$, $\mathrm{df}=2, \mathrm{P}<0.001)$, and for the angular speed: $95 v s 131$ angular degrees/ $\mathrm{cm}\left(\chi^{2}=20.04, \mathrm{df}=2, \mathrm{P}<0.001\right)$. This is in agreement with the ants' higher general activity during the night (see the above subsection).

Orientation: Numerical results are given in Table 2, line 3 and photos are shown in Figure 2. Under normal lighting, the ants better oriented themselves towards a source of alarm pheromone during the night than during the day. The ants' orientation equaled 35.4 angular degrees during the night and 44.9 angular degrees during the day, the latter result meaning a less accurate orientation. The difference was significant $\left(\chi^{2}=7.44, \mathrm{df}=2,0.02 \sim \mathrm{P}<0.05\right)$. This could be due to a better olfactory perception during the night, the ants using probably more their olfactory perception during the night and more their visual perception during the day.

Audacity: Numerical results are given in Table 2, line 4; photos are shown in Figure 2. Under normal lighting conditions, the ants were more inclined to come onto an unknown apparatus during the night than during the day. Meanly 5.00 ants were counted there during the night and 1.25 ones during the day. The difference was significant $(\mathrm{N}=5, \mathrm{~T}=15, \mathrm{P}=0.031)$ and is in agreement with the ants' larger activity during the night.

Tactile perception: Numerical results are given in Table 2, two last lines (l=linear speed; a=angular speed), and photos are shown in Figure 2. While living under normal lighting, the ants were somewhat more sensitive to the rough character of the experimental substrate during the night than during the day. They moved on this substrate a little more slowly during the night $(5.1 \mathrm{vs} 6.8 \mathrm{~mm} / \mathrm{sec})$. The difference between these two linear speeds was significant: $\chi^{2}=8.74$, $\mathrm{df}=1,0.01<\mathrm{P}<0.02$. They moved also a little more sinuously on the rough substrate during the night (243 vs 198angular degrees $/ \mathrm{cm}$ ), but this difference was not significant $\left(\chi^{2}=2.74, \mathrm{df}=2,0.20<\mathrm{P}<0.30\right)$. Nevertheless, the ants' perception seemed to be somewhat larger during the night than during the day (e.g. see the result for tactile perception, the result about the ants' orientation and that related below about social relationship).

Social relationship: Numerical results are given in Table 3, upper part; photos can be seen in Figure 2. Under normal lighting conditions, the ants were very slightly more aggressive against nestmates during the day than during the night. However, they never gripped, tried to sting or stung their nestmates. The only observed behaviors were 'doing nothing' (level 0), antennae contact (level 1) and mandibles opening (level 2). During the day, the numbers of ants presenting these three behaviors were 114, 68 and 21 respectively (the variable 'a' equaling thus 0.12 ), and the numbers of ants exhibiting these three behaviors during the night were 119, 53 and 7 (the variable 'a' equaling thus 0.04). This difference between the ants' behavior during the day and the night was significant: $\chi^{2}=7.42, \mathrm{df}=2,0.02 \sim \mathrm{P}<0.05$. Ants might better or sooner perceive their nesmates' cuticular odor during the night, being then more sensitive to olfactory elements.

Learning and memory: Numerical results are given in Table 3, lower part; two photos are shown in Figure 2. Under normal lighting conditions, the ants rapidly acquired conditioning to the green hollow cube presented during training. After 12 training hours, they already responded to the cue with a mean score of $70 \%$. They reached their maximum conditioning score after 36 training hours, or somewhat less. After more than 48 training hours, the ants presented somewhat lower conditioning scores, i.e. $80 \%$ instead of $85 \%$ as it is commonly the case for any conditioning or learning. Meanly, they equally responded to the visual cue during the day and during the night. Twelve and even 24 hours after the removal of the green cube, the ants still presented a conditioning score of $70 \%$. Unexpectedly, 36 hours after the cue removal, they exhibited a conditioning score of $80 \%$. Then, 48 and 60 hours after the cue removal, the ants presented a conditioning score of $70 \%$ and $75 \%$ respectively. They thus retained about $25 \%$ (i.e. a $75 \%$ score $36-60$ hours after removal of the cue minus a $50 \%$ score corresponding to no conditioning) of their $35 \%$ acquired conditioning (i.e. a $85 \%$ score acquired through conditioning minus a $50 \%$ score corresponding to no conditioning), presenting therefore an excellent long term memory. With additional nocturnal continuous artificial
lighting, results obtained during the day and the night

General activity, meat and sugar water consumption: Numerical results are given in Table 1. Under additional nocturnal lighting, the ants were less active, consumed somewhat less meat and drank a little less sugar water during the night than during the day, but these three kinds of observations were not statistically significant. Meanly, we observed during the night $v s$ during the day for the activity: 2.9 vs 3.2 ants $(\mathrm{N}=6, \mathrm{~T}=+4.5,-16.5, \mathrm{P}=0.133)$, for meat consumption: 0.3 vs 0.5 ants $(\mathrm{N}=5, \mathrm{~T}=+2,-13, \mathrm{P}=0.094)$, and for sugar water consumption: 2.1 vs 1.9 ants $(\mathrm{N}=6, \mathrm{~T}=+4,-17, \mathrm{P}=0.094)$.

Linear and angular speed: Numerical results are given in Table 2, lines 1 and 2, and two photos are shown in Figure 3. With additional nocturnal lighting, the ants walked at a low linear speed, with a large sinuosity, and presented no difference of locomotion between the day and the night (linear speed: night $v s$ day: $8.2 v s 8.0 \mathrm{~mm} / \mathrm{sec}, \chi^{2}=3.50$, $\mathrm{df}=2,0.10<\mathrm{P}<0.20$; sinuosity: night $v s$ day: 163 vs $165 \mathrm{ang} . \mathrm{deg} / \mathrm{cm}$, $\chi^{2}=2.14, \mathrm{df}=2,0.30<\mathrm{P}<0.50$ ).

Orientation: Numerical results are given in Table 2, line 3; two photos are shown in Figure 3. The ants living under additional nocturnal 
lighting did not well orient themselves to a tied nestmate, this occurring during the day and the night, with no statistical difference between the two situations ( 74.9 vs $\left.62.2 ; \chi^{2}=1.36, \mathrm{df}=2, \mathrm{P} \sim 50\right)$.

Audacity: Numerical results are given in Table 2, line 4, and two photos in Figure 3. The audacity of ants living under additional nocturnal lighting was weak, during the day as well as the night, and there was no statistical difference between that presented at each of these two periods ( 1.05 vs $0.80 ; \mathrm{N}=4, \mathrm{~T}=+8.5,-1.5, \mathrm{P}=0.156)$.

Tactile perception: Numerical results are given in Table 2, the two last lines, and two photos are shown in Figure 3. The ants living under additional nocturnal lighting had their linear and angular speeds affected by the rough character of the experimental substrate. Their linear speed slightly more decreased during the night (day $v s$ night: $\left.\chi^{2}=5.48, \mathrm{df}=1,0.01<\mathrm{P}<0.02\right)$, but their sinuosity did not increase $(185$ vs $\left.180 ; \chi^{2}=0, \mathrm{df}=1, \mathrm{P}=1\right)$.

Social relationship: Numerical results are given in Table 3, upper part; two photos are shown in Figure 3. Ants living under additional nocturnal lighting did not strongly aggressed the opponent nestmates but rarely stayed doing nothing and very often opened their mandibles when encountering them. There was no statistical difference between the ants' behavior during the day and the night $\left(\chi^{2}=0.48, \mathrm{df}=2\right.$, $0.70<\mathrm{P}<0.80$ ).

Learning and memory: Numerical results are given in Table 3, lower part; two photos are shown in Figure 3. After 12, 24, 36, 48, and 60 training hours respectively, 6, 4, 4, 6, 4 ants of colony A gave the correct response, while 4, 6, 6, 4, 6 ants of colony B did so. Consequently, at each of these five testing sessions, the ants' conditioning score equaled $50 \%$, what corresponded to an absence of learning. The ants living under additional nocturnal lighting having learned nothing in the course of 60 training hours, it was non-sense to examine if their middle and long term memory were impacted.

\section{Comparison of results obtained under the two kinds of lighting conditions}

General activity, meat and sugar water consumption: While living under normal lighting, the ants were more active and eat more during the night than during the day. This did not occur for ants living under additional nocturnal lighting (see previous subsections). This is why the comparison between these three traits presented by ants living under the two kinds of lighting revealed that the difference between them was large during the night and small during the day. Indeed, comparing nocturnal vs normal lighting, we obtained for what occurred during the day: activity: 3.2 vs 7.9 ants, $\mathrm{N}=6, \mathrm{~T}=21, \mathrm{P}=0.016$; meat consumption: 0.5 vs 1.4 ants, $\mathrm{N}=6, \mathrm{~T}=+4,-17, \mathrm{P}=0.109$; sugar water consumption: 1.9 vs 2.3 ants, $\mathrm{N}=6, \mathrm{~T}=+6,-15, \mathrm{P}=0.219$; and for what occurred during the night: activity: 2.9 ss 17.7 ants, $\mathrm{N}=6, \mathrm{~T}=-21$, $\mathrm{P}=0.016$; meat consumption: 0.3 vs 3.6 ants, $\mathrm{N}=6, \mathrm{~T}=-21, \mathrm{P}=0.016$; sugar water consumption: 1.7 vs 5.6 ants, $\mathrm{N}=6, \mathrm{~T}=-21, \mathrm{P}=0.016$. Consequently, continuous lighting decreased the ants' activity and food consumption essentially during the night (at the time during which ants living under normal lighting were the more active and eat more), but also, at a lower extend, during the day. Continuous lighting impacted thus all the time the ants' health and physiology.

Linear and angular speeds: The linear speed of ants living under additional nocturnal lighting was lower than that of ants living under normal lighting. We obtained for the day $8.0 v s 10.3 ; \chi^{2}=23.55, \mathrm{df}=2$, $\mathrm{P}<0.001$, and for the night 8.2 vs $13.3 ; \chi^{2}=64.11, \mathrm{df}=2, \mathrm{P}<0.001$, the largest difference occurring thus during the night. The sinuosity of ants living under artificial continuous lighting was higher than that of ants living under normal lighting. We obtained for the day 165 vs 131, $\chi^{2}=18.72, \mathrm{df}=2, \mathrm{P}<0.001$; and for the night $163 v \mathrm{~s} 95, \chi^{2}=53.28, \mathrm{df}=2$, $\mathrm{P}<0.001$, the largest difference occurring thus again during the night. Living under lighting conditions during the night impacted thus the locomotion essentially at that moment, i.e. during the night, but also during the day.

Orientation: The orientation of ants living under additional nocturnal lighting was far less good than that of ants living under normal lighting, the impact of additional nocturnal lighting being greater during the night than during the day. Indeed, the difference of orientation between the ants living under the two kinds of lighting was statistically estimated at $0.01<\mathrm{P}<0.02\left(\chi^{2}=9.03, \mathrm{df}=2\right)$ on the basis of values recorded during the day (62.2 vs 44.9), and at $\mathrm{P}<0.001$ $\left(\chi^{2}=9.48, \mathrm{df}=2\right)$ on the basis of values recorded during the night ( 74.9 vs 35.4). An artificial continuous lighting impacted thus the orientation ability and probably also the ants' perception of social pheromones, essentially during the night (while lighting is abnormal) but also, at a lower extend, during the day.

Audacity: Comparison with what occurred under normal lighting showed that, with additional nocturnal lighting, the ants' audacity was not significantly lower during daylight $(0.80$ vs $1.25 ; \mathrm{N}=5, \mathrm{~T}=+3$, $-12, \mathrm{P}=0.156)$, but well during the night ( 1.05 vs $5.00 ; \mathrm{N}=5, \mathrm{~T}=15$, $\mathrm{P}=0.031$ ). Once more, a continuous lighting impacted the physiology and the ethology of the experimented animals essentially during the night, but also slightly during the day.

Tactile perception: Compared with ants living under normal lighting, those under additional nocturnal lighting were less affected by the rough character of the substrate, and this essentially during the night. Indeed, the difference of locomotion between ants living under the two kinds of lighting was larger during the night. We obtained for the day, a linear speed of 8.3 vs $6.8: \chi^{2}=9.6, \mathrm{df}=1,0.001<\mathrm{P}<0.01$; and a sinuosity of $180 v s$ 198: $\chi^{2}=4.1, \mathrm{df}=1,0.02<\mathrm{P}<0.05$; and for the night, a linear speed of 7.2 vs $5.1: \chi^{2}=24.12, \mathrm{df}=1, \mathrm{P}<0.001$; and a sinuosity of 185 vs $243: \chi^{2}=; 7.85, \mathrm{df}=1,0.001<\mathrm{P}<0.01$. Consequently, a continuous lighting decreased the ants' tactile perception, and this essentially during the night but persisted also during the day.

Social relationship: There was a difference between the slightly aggressive behaviors of ants living under additional nocturnal lighting and the non aggressive behavior presented during the day and the night by ants living under normal lighting. The difference of aggressiveness occurring during the night was larger than that occurring during the day. Indeed, we obtained $\chi^{2}=90.87$ for the values recorded during the night and $\chi^{2}=58.80$ for the values recorded during the day, these two values of $\chi^{2}$, with $\mathrm{df}=2$, leading to a significance level of $\mathrm{P}<0.001$. Consequently, artificial nocturnal lighting impacted the ants' relationships, inducing them to ignore or slightly aggress their nestmates, while under normal lighting ants usually had no aggressive social relationships. The impact was greater during the night but also and significantly existed during the day. Such an impact may weaken the survival potential of the species.

Learning and memory: The learning of ants living under additional nocturnal lighting was non-existent and thus different from that of ants living under normal lighting $(\mathrm{N}=5, \mathrm{~T}=15, \mathrm{P}=0.031)$. Hence, under nocturnal lighting, the ants' middle and long term memories could not be assessed and compared with that of ants under normal lighting.

\section{Discussion}

Negative consequences of nocturnal light on the biodiversity of a wide spectrum of diurnal animals were already exposed more than one 
decade ago. ${ }^{1}$ Nowadays, in most parts of the world, artificial lighting occurs during the night. However, most living organisms are adapted to a succession of lighted and dark periods. A continuous lighting may thus perturb them and has effectively been proved to do so, including humans. Several works have demonstrated such an impact (see the introduction section), but few works concern the invertebrates, and among them the insects, and nearly no work deals with the effect of nocturnal light on their physiology and ethology, except those examining their reproductive efficiency.

Here we studied the potential effects of nocturnal light on eleven physiological and ethological traits using an ant species as a model. We found that all the studied traits were impacted, essentially during the night, but also, at a lower extend, during the day. The ants' activity, food consumption, locomotion, audacity, tactile perception, social relationships and learning (and thus memorization) capabilities were significantly reduced. Moreover, although the negative effects of nocturnal artificial lighting were essentially observed during the night time, they were also, at a lower but significant extent, observed during the day (Table 4). Our work also showed that animals which are $a$ priori not expected to be directly influenced by artificial nocturnal light can even be impacted at any time of the day, when such an artificial lighting is set during normal darkness. This recalls the result of an ecological study which compared nocturnal and diurnal invertebrate communities under street lighting: the composition of these communities was affected by the artificial nocturnal lighting not only during the night but also remained affected during the day. ${ }^{12}$

Table 4 Summarized comparison of traits (column I) obtained during the night vs the day, under the two kinds of lighting condition (columns 2 and 3), and obtained under + nocturnal vs normal lighting, during the night and the day (columns 4 and 5). Numerical values are given in Tables I, 2, 3 and statistics in the text. +: significant increase, -: significant decrease, $(+)$ : non-significant increase, $(-)$ : non-significant decrease, $=$ : no change, ${ }^{*}$ : nocturnal behavior being better than diurnal behavior, ${ }^{* *}$ : behavior under nocturnal lighting being worse than behavior under normal lighting, low: behavior of poor quality, excellent behavior of good quality. Nocturnal lighting impacted thus the ants' physiology and ethology, essentially during the night but also at a lower extend, during the day

\begin{tabular}{|c|c|c|c|c|}
\hline \multirow{2}{*}{ Traits } & \multirow{2}{*}{$\begin{array}{l}\text { normal } \\
\text { light: } \\
\text { night vs day }\end{array}$} & \multirow{2}{*}{$\begin{array}{l}\text { + nocturnal } \\
\text { light: } \\
\text { night vs day }\end{array}$} & \multirow{2}{*}{$\begin{array}{l}\text { night: } \\
\text { + nocturnal } \\
\text { vs normal }\end{array}$} & \multirow{2}{*}{$\begin{array}{l}\text { day: } \\
\text { + nocturnal } \\
\text { vs normal }\end{array}$} \\
\hline & & & & \\
\hline Activity & + & $(-)$ & - & - \\
\hline $\begin{array}{l}\text { Meat } \\
\text { Consumption }\end{array}$ & + & $(-)$ & - & $(-)$ \\
\hline $\begin{array}{l}\text { Sugar water } \\
\text { consumption }\end{array}$ & + & $(-)$ & - & $(-)$ \\
\hline Linear speed & + & $=$ & - & - \\
\hline Angular speed & $-*$ & $=$ & $+* *$ & $+* *$ \\
\hline Orientation & + & $=$; low & - & - \\
\hline Audacity & + & $=$; low & - & $(-)$ \\
\hline $\begin{array}{l}\text { Tactile } \\
\text { perception }\end{array}$ & + & $(+)$ & - & - \\
\hline $\begin{array}{l}\text { Social } \\
\text { relationships }\end{array}$ & + & $=$ & - & - \\
\hline Learning & $=$; excellent & $=$; no learning & - & - \\
\hline Memory & $=$; excellent & unfulfilled & unfulfilled & unfulfilled \\
\hline
\end{tabular}

Let us give an example of a potential impact of nocturnal lighting on an ant species. We have shown that the workers of the ant Myrmica ruginodis have a good visual perception and can see very small luminous points located above them. ${ }^{30}$ As they forage during the night, it is possible that they use celestial cues for navigating. Therefore, they could be perturbed by nocturnal light pollution.

The biological traits we here examined are surely not the only ones to be affected by anthropogenic nocturnal lighting. The individuals' different cognitive capabilities, their tiredness, care of young individuals, motivation, rapidity in performing several tasks, accuracy of information reception, as well as other traits not presently thought about, could be affected when living under artificial nocturnal lighting. No doubt that such traits, or at least several of them, could also be affected by nocturnal lighting, the animals being either nocturnal or diurnal.

Decrease of animal populations may be at least partly explained by human artificial excessive nocturnal lighting. Plants are also impacted by light pollution and so may affect an entire ecosystem. ${ }^{31}$

Humans depend on nature for their survival; they must preserve it. A few solutions for reducing the light pollution have been already used or at least proposed (e.g. decreasing the light intensity as well as the number of lighted areas). Such advices are given, among others, in two last references. ${ }^{32,33}$

\section{Conclusion}

Light pollution, above all the artificial nocturnal lighting, is nowadays a nearly worldwide problem since it largely impacts the life of humans, vertebrates and invertebrates (diurnal as well as nocturnal), the plants and thus the ecosystems. Impacts on sleeping, reproduction, migration, and other well visible biological traits are well documented, but those on other not easily perceptible ethological and physiological traits are less well known, especially concerning insects. Using ants as a model, we here showed that nocturnal lighting significantly decreases their activity, food consumption, locomotion, orientation, audacity, tactile perception, social relationships, learning and memory, and this not only during the night, but also at a lower extend during the day.

\section{Acknowledgments}

None.

\section{Funding}

None.

\section{Conflicts of interest}

We affirm having no conflict of interest concerning the subject (light pollution) experimentally approached in the present work. We also declare having maintained the ants in the best conditions possible.

\section{References}

1. Longcore T, Rich C. Ecological light pollution. Frontiers in Ecology and the Environment. 2004; 2(4):191-198.

2. Chepesiuk R. Missing the dark: health effects of light pollution. Environ Health Perspec. 2009;117(1):A23-A27.

3. Beier P. Effects of artificial night lighting on terrestrial mammals. In Rich C, Longcore T, editors. Ecological consequences of artificial night lighting. Covelo, California: Island Press; 2006:19-42.

4. Stone EL, Harris S, Jones G. Impacts of artificial lighting on bats: a review of challenges and solutions. Mammalian Biology. 2015;80(3):213-219. 
5. Robert KA, Lesku JA, Partecke J, et al. Artificial light at night desynchronizes strictly seasonal reproduction in a wild mammal. Proc Biol Sci. 2015;282:20151745.

6. Schwartz SM. Effects of constant bright illumination on reproductive processes in the female rat. Eurosci Biobehav Rev. 1982;6(3):391-406.

7. Perry G, Buchaman BW, Fisher RN, et al. Effects of artificial night lighting on Amphibians and Reptiles in urban envitonments. Herpetological Conservation. 2008;3:239-256.

8. Gauthreaux SA Jr, Belser CG. Effects of artificial night lighting on migrating birds. In: Rich C, Longcore T, editors. Ecological consequences of artificial night lighting. Covelo, California: Island Press; 2006:67-93.

9. Santos CD, Miranda AC, Granadeiro JP et al. Effects of artificial illumination on the nocturnal foraging of waders. Acta Oecologica. 2010;36(2):166-172.

10. Yorzinski JL, Chisholm S, Byerley SD, et al. Artificial light pollution increases nocturnal vigilance in peahens. PeerJ3:e1174. 2015;3(8):e1174.

11. Manfrin A, Surger G, Larsen S. et al. Artificial light at night affects organism flux across ecosystem boundaries and drives community structure in the recipient ecosystem. Front Environ. Sci. 2017;5:61.

12. Davies TW, Bennie J, Gaston KJ. Street lighting changes the composition of invertebrate communities. Biol Lett. 2012;8:764-767.

13. Owens ACS, Lewis SM. The impact of artificial light at night on nocturnal insects: a review and synthesis. Ecology and Evolution. 2018;8(22):11337-11368.

14. Hagen O, Santos RM, Schlindwein MN, et al. Artificial Night Lighting Reduces Firefly (Coleoptera: Lampyridae) Occurrence in Sorocaba, Brazil. Adv in Entomol. 2015;3:24-32.

15. Firebaugh A, Haynes KJ. Experimental tests of light-pollution impacts on nocturnal insect courtship and dispersal. Oecologia. 2016;182(4):12031211.

16. Cammaerts MC, Cammaerts D. Comparative outlook over three Myrmica species' biotopes and foragers' know-how. Biologia. 2014;69:1051-1058.

17. Cammaerts MC, Cammaerts R. Ontogenesis of ants' cognitive abilities (Hymenoptera, Formicidae). Advanced Studies in Biology. 2015; 7:335348.

18. Cammaerts MC. Ants' ability in solving simple problems. Int J Biology. 2017;9(3):26-37.

19. Cammaerts MC, Cammaerts R. Ants are at the first stage of the notion of zero. Int J Biol. 2019;11(1):54-65.
20. Cammaerts MC. Ants as biological models for studying effects of substances used by humans. JSM Anatomy and Physiology. 2016;1:1003.

21. Cammaerts MC. Some findings on ants as models, which should be considered for caring of humans. MOJ Biology and Medicine. 2017;1(5):125-128.

22. Cammaerts MC. Ants as models for examining potential adverse effects of products used by humans. JSM Anatomy and Physiology. 2018;3(1):1016.

23. Cammaerts MC. Brief report of the effects of seven human drugs studied on ants as models. MOJ Biology and Medicine. 2019;4(2):42-47.

24. Cammaerts MC, Cammaerts D. Potential harmful effects of carbamazepine on aquatic organisms, a study using ants as invertebrate models. Int $J$ of Biology. 2015;7(3):75-93.

25. Cammaerts MC, Cammaerts R. Aspartame increases food demand and impacts behavior: a study using ants as models. Acta Biomedica Scientia. 2016;3:9-23.

26. Cammaerts MC, Rachidi Z, Cammaerts R. Physiological and ethological effects of alprazolam, using ants as biological models. World Journal of Pharmaceutical Sciences. 2016;4(6):474-489.

27. Cammaerts MC, Cammaerts R. Adverse effects of etoricoxib, a selectively inhibiting cyclo-oxygenase-2 anti-inflammatory drug, assessed on ants used as a model. EC Pharmacol Toxicol. 2019;7(5):373-392.

28. Siegel S, Castellan NJ. Non-parametric statistics for the behavioural sciences. Singapore: McGraw-Hill; 1989.

29. Cammaerts MC, Morel F, Martino F. et al. An easy and cheap softwarebased method to assess two-dimensional trajectories parameters. Belg $J$ Zool. 2012;142:145-151.

30. Cammaerts MC. The visual perception of the ant Myrmica ruginodis (Hymenoptera - Formicidae). Biologia. 2012;67:1165-1174.

31. Bennie J, Davies TW, Cruse D et al. Ecological effects of artificial light at night on wild plants. J of Ecology. 2016;104:611-620.

32. Gaston KJ, Davies TW, Bennie $\mathrm{J}$ et al. Reducing the ecological consequences of night-time pollution: options and developments. $J$ Applied Ecology. 2012;49(6):1256-1266.

33. Sordello R. Methodological approaches to take into account light pollution in ecological networks. Vertigo - the electronic journal in environmental sciences. 2017;17(3). 